\title{
A PHOTO IS WORTH A THOUSAND WORDS: HOSTS UPSET BY THE NEW NON- DISCRIMINATION POLICY OF MOVING BEYOND PHOTOS ON AIRBNB
}

\author{
Hongrui ZHU* \\ Independent researcher, 106 Carden Street, Guelph, Ontario, Canada, N1H 3A3, e-mail: hongrui.zhu1988@gmail.com \\ Mehri YASAMI \\ Prince of Songkla University, Faculty of Hospitality and Tourism, Kathu, Phuket, Thailand, e-mail: mehri.yasami@gmail.com
}

\begin{abstract}
Citation: Zhu, H., \& Yasami, M. (2021). A PHOTO IS WORTH A THOUSAND WORDS: HOSTS UPSET BY THE NEW NONDISCRIMINATION POLICY OF MOVING BEYOND PHOTOS ON AIRBNB. GeoJournal of Tourism and Geosites, 35(2), 348354. https://doi.org/10.30892/gtg.35212-658
\end{abstract}

\begin{abstract}
In attempting to tackle the alleged digital discriminatory practices, Airbnb has established a series of non-discrimination policies, and the recent one was that guests' photos will not be disclosed to hosts until they accept the booking requests from prospective guests. This new non-discrimination policy has sparked heated discussion among the hosts. This study sets out to explore the overlooked narratives of Airbnb hosts towards this recent non-discrimination policy. A total of 1,211 posts shared by numerous hosts were collected from the Airbnb community website. These posts were analyzed by undertaking a co-occurrence analysis to identify key concepts and the connections among these key concepts that revolved around the new non-discrimination policy. Nine key concepts, namely, home, safety, stranger, risk, hotel, third-party booking, trust, community, and discriminate, and their connections, were presented in a visual network generated via Gephi to show what concerned the hosts after Airbnb implementing this policy. This study also offers in sights into why such a new policy that aimed at fighting against discrimination on Airbnb may put hosts at a disadvantaged position or vulnerable status. It also offers significant practical implications regarding the important roles played by photos on Airbnb.
\end{abstract}

Key words: Airbnb, peer-to-peer accommodation, profile photos, digital discrimination, co-occurrence analysis

\section{INTRODUCTION}

Airbnb is an online sharing platform where individuals can share their private space within their homes or rent out their properties entirely to holidaymakers and/or other accommodation seekers (Guttentag, 2019). The emergence of peer-to-peer (P2P) accommodation platforms, exemplified by Airbnb, has revolutionized the traditional accommodation practices within the hospitality and hotel sector (Guttentag, 2015; Mody et al., 2019). Airbnb not only allows guests to have access to the private space of the hosts and facilitate the interactions among them but also enables guests to have an authentic experience of neighborhood life (Tuttle, 2014). Thus, Airbnb has witnessed exponential growth and enjoyed tremendous popularity within the P2P accommodation section since its inception in 2008 (Boros et al., 2018; Camilleri and Neuhofer, 2017; Oskam and Boswijk, 2016; Pizam, 2014). With the unprecedented development of Airbnb, many guests have voiced their experiences concerned about alleged digital discrimination when using Airbnb on the ground of sexual orientation, religion, and/or race (Ahuja and Lyons, 2017; Cui et al., 2020; Edelman et al, 2017). When facing the situation, Airbnb has strived great efforts to fight against alleged discriminatory practices on its platform by introducing a range of non-discrimination policies, such as promoting instant booking among its hosts and forming a special team to work on resolving the issue, etc. (Airbnb, 2016; Levin, 2016). Further in October 2018, Airbnb announced a new, specific non-discrimination policy of moving beyond photos, which is to conceal the profile photos of guests from hosts until the booking is confirmed. Previous studies have suggested that photos on Airbnb help connect hosts with guests in their first interactions (Ert et al., 2016; Farmaki and Kladou, 2020), and host assess the potential risks of granting permission to guest booking requests based on the features of their profile photos (Karlsson et al., 2017). Although Airbnb has taken a series of actions to fight against discrimination and academic scholars have begun to look into the potential discrimination encountered by Airbnb guests on the platform; minimum attention has been focused on how these nondiscrimination policies affect Airbnb hosts and/or what roles these hosts have played when policymakers considered introducing new policies. Given the recent controversial policy implemented by Airbnb, the necessity of understanding how Airbnb hosts react to this policy is imminent. Built on this premise, this paper sets out to explore how these Airbnb hosts have responded by examining their responses and concerns to this new policy at large drawn from the threads posted on Airbnb Community - an affiliated website where Airbnb users can proactively share their concerns over their Airbnb experiences. Also, this paper may contribute an insightful understanding of hosts' perspectives on the matter of alleged discrimination on Airbnb, which may provide valuable implications for Airbnb to contemplate on its policy-making process and the trusting-building within the community.

\section{LITERATURE REVIEW}

1. Digital Discrimination

Digital discrimination refers to a variety of situations where individuals or groups are treated unfavorably or unfairly as 
compared to other individuals or groups on the ground of their race, background, and/or particular characteristics on the Internet (Cheng and Foley, 2018). In the sphere of P2P accommodation, the complaints about racial discrimination encountered on Airbnb have attracted media and public attention (Glusac, 2016). As mentioned above, Airbnb has implemented a series of nondiscrimination measures to tackle this issue ever since (Airbnb, 2016; Benner, 2016) and its efforts are still on-going.

Scholars have begun to look into the potential discriminatory practices on Airbnb. Edelman and Geradin (2015) have lifted the curtain and probed into the alleged discriminatory practices, such as race, sexual orientation, and religion, and so on, that occurred on Airbnb. Since then, studies have adopted field experiments by creating fake accounts on Airbnb with white names and distinctive ethnic ones and the results have indicated that guests with white names are more likely to be accepted compared to those with ethnic names when making bookings on Airbnb (Cui et al., 2020; Edelman et al., 2017). Similarly, Ahuja and Lyons (2017) suggest that male gay couples are more likely to encounter discriminatory practices when making booking requests on Airbnb due to sexual orientation. Research has also found that ethnic hosts in San Francisco, such as Hispanics and Asians, tended to price their listing less than their white counterparts by 8 to $10 \%$ to attract potential guests, indicating that the reverse discrimination from Airbnb guests occurred when they choose a place to stay on Airbnb (Kakar et al., 2018). In a recent study, Farmaki and Kladou (2020) have developed a framework to examine the sources and types of discriminatory behaviors among Airbnb hosts and shown useful insights and a greater understanding of the causes of discrimination and the way to eliminate it.

2. Photos and Power Dynamics on Airbnb

The importance of profile photos on $\mathrm{P} 2 \mathrm{P}$ accommodation platforms has also begun to draw attention from the academic discourse. Edelman and Geradin (2015) argue whether it is necessary to allow Airbnb hosts to see guests' photos and names, as it may lead to potential discrimination against the guests. However, studies have suggested that a profile photo is of great significance within a home-sharing community like Airbnb, because it can build trust and connections between guests and hosts and potentially reduce risks that both parties may perceive (Kakar et al., 2018; Murphy, 2016), which contributed to the satisfaction of the guests (Bar et al., 2016; Boros et al., 2018). Meanwhile, by focusing on hosts' profile photos, scholars have confirmed that a lack of profile photos from hosts may reduce the perceived trustworthiness among guests thus leading to reduced booking tendencies (Ert et al., 2016; Fagerstrøm et al., 2017). It is evident that a profile photo plays a significant role during the process of accepting booking requests. Thus, policymakers should have considered the impact on hosts accepting booking requests from guests without photos before implementing such a new policy.

The regulations and policies implemented on the platform can trigger a series of power issues among hosts, guests, and the platform. P2P accommodation platforms exert mediating impacts on both hosts and guests (Cheng and Foley, 2018) so that the equality and balance between two parties are maintained and empowered (Dolnicar, 2018). The double-blind review system on Airbnb is also a representation of power equality between hosts and guests (Farmaki and Kaniadakis, 2020). Displaying profile photos from both parties and photos of the rented place from hosts prior to booking confirmation facilitates the trust-building between hosts and guests, which is also seen as a symbol of equal power. However, Airbnb hosts began to feel that the power balance was shifted to guests as a result of Airbnb taking a more guest-center approach (Farmaki et al., 2019; 2020), such as pushing hosts to use the function of Instant Booking to accept requests from guests by controlling the display orders of hosts' listings and striping hosts' Superhost Badge if they turn down or cancel a booking (Farmaki and Kaniadakis, 2020). Another example is that Farmaki and Kladou (2020) suggest that several hosts on Airbnb mentioned that they are very likely to be affected by this new non-discrimination policy of not disclosing profile photos; consequently, they have become more powerless and less flexible when it comes to accepting booking requests. Due to the nature of home-sharing that mixes personal with professional space, the absence of regulations, and the issues of property rights, Airbnb hosts have started to form self-regulating and self-empowering groups so that they can discuss issues and find solutions for various scenarios encountered when hosting guests, which is also a way to regain a certain level of power (Farmaki and Kaniadakis, 2020). Other research has suggested that the introduction and implementation of the new non-discrimination policy of disclosing guests' profile photos can potentially restrict hosts' ability to select prospective guests (Farmaki and Kladou, 2020), which further weakens hosts' power and leaves them at a disadvantageous position on Airbnb. It is of great necessity to take the concerns voiced by Airbnb hosts into consideration with regard to introducing new policies and regulations to tackle the issue of discriminatory practices on P2P accommodation platforms like Airbnb. Thus, a much more nuanced understanding of how Airbnb hosts responded to this new policy is needed to understand and address this issue.

The implementation of such a new policy of concealing guests' profile photos prior to booking acceptance has made a huge splash among Airbnb users, in particular its hosts. More importantly, this policy of concealing guests' photos has mirrored serious contradictions between the two anti-discrimination reports issued by the Airbnb team, which summarized the actions that Airbnb has taken to combat discrimination as well as build trust towards a more inclusive platform and community (Murphy, 2016; 2019). The first one emphasized that profile photos from both parties play an essential role in fostering interactions and trust within the Airbnb community, thus guests should show their images rather than hiding under the disguise of anonymity when they try to look for a place on Airbnb (Murphy, 2016). However, the latest report (Murphy, 2019) advocated the new nondiscrimination policy of hosts receiving the guests' photos after they accept the booking request. Thus, it is of great necessity to examine the attitudes of hosts towards such a controversial non-discrimination policy due to the mixed message sent by Airbnb. Airbnb brands itself as "a trusted community marketplace for people to list, discover, and book unique accommodations around the world" (Murphy, 2016, p. 2). However, the new non-discrimination policy may render it difficult for hosts to build trust and rapport with potential guests whose profile photos are nowhere to be seen when hosts try to make decisions regarding booking requests. Also, Farmaki and Kladou (2020) confirm Airbnb hosts are concerned with their host rights under this new policy. Although this research has briefly discussed the attitudes of some hosts held towards this policy, it paid more attention to the underlying reasons for the discriminatory practices of hosts that occurred on Airbnb. Built on the reviewing of extant literature, 
limited academic attention has been given to how hosts respond to these non-discrimination policies implemented by Airbnb. Therefore, this study attempts to provide a nuanced understanding of the reactions of Airbnb hosts towards the new policy of not disclosing guests' photos until booing is confirmed and how they might have been affected by this policy at large.

\section{METHODOLOGY}

After Airbnb introduced this new non-discrimination policy of not disclosing guests' profile photos to prospective hosts until the confirmation of the booking requests, it had sparked heated discussion among Airbnb users, particularly, hosts. This study sets out to offer a nuanced understanding of how Airbnb hosts responded to this new non-discrimination policy. These opinions were collected from Airbnb Community where they had vented their personal opinions about this policy. It is a website that helps Airbnb, guests, and hosts to communicate and discuss matters that are related to their Airbnb experiences. By January 2020, a total of 1,211 posts in this regard had been collected and analyzed. The collection of users' posts from a public online domain does not fall in the scope of human-related studies (Kozinets, 2010); therefore, it is not required to obtain consent and ethical approval for this research. These online posts were put into an Excel spreadsheet for data analysis, which consisted of several steps. First of all, the content of these posts was familiarized with repeated reading. In this step, certain posts were excluded from the original dataset based on three criteria: (1) posts that did not offer relevant opinions on this nondiscrimination policy, (2) posts that merely offered comments on other hosts' posts but not on the policy itself, and (3) posts that were repeatedly posted by the same host. This screening step thus enriched posts that were used as a refined dataset for subsequent data analysis. In the second step, the content of each post from the refined dataset was decomposed into tokens, i.e. meaningful words and phrases, and the process is termed tokenization. For instance, one host posted below:

Hosts need to know who is coming to the door of their home. Airbnb is a home rental platform, not hotel. When a host opens their home to a stranger, they expect a gracious friend, not an entitled customer to take over their life. Yes, I absolutely want to see the face of the guest. It is good manners. This is for the safety and comfort of both sides. The above post has been decomposed into the following tokens: hosts; coming to the door of their home; home rental platform; not hotel; opens their home to a stranger; a gracious friend; an entitled customer; take over their life; see the face of the guest; good manners; safety and comfort. The third step involved the selection of key tokens based on their degree of relevancy. To isolate key tokens, the primary elements of this non-discrimination policy need to be revisited. It states that hosts are not allowed to view the profile photos of potential guests until the acceptance of guests' booking request; accordingly, this policy revolves around three key aspects: the discrimination issues, the hosts' rights at their own premises, and the relationship and dynamics among all Airbnb parties. Measured in the relevancy to this policy, some of the tokens extracted from the posts would be too general to be included as key tokens. Taking the above post as an example, the following key tokens were isolated: coming to the door of their home; not hotel; opens their home to a stranger; safety and comfort. The fourth step was to synthesize key tokens into key concepts. Key

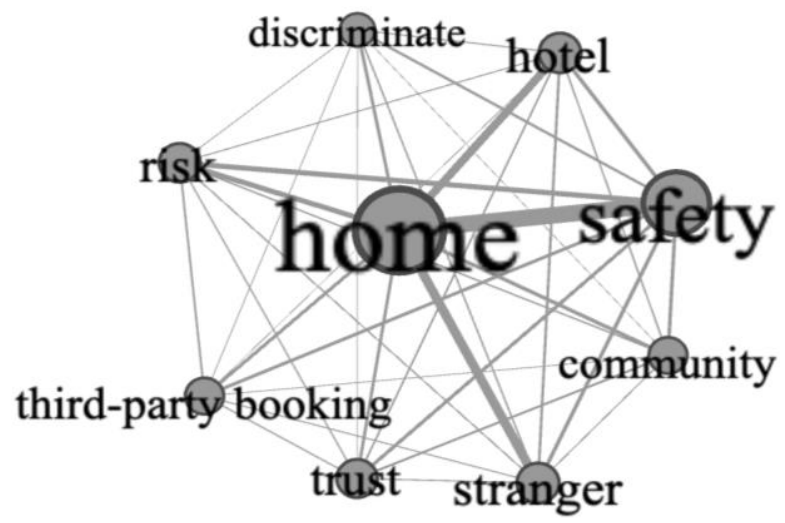

Figure 1. Visualized network of key concepts tokens have been condensed into concise words or phrases without changing the meanings. For example, the token "guests who are employees booked by their employer", which indicates that the guests did not make the booking themselves, has been condensed into "third-party booking". Also, tokens have been conflated to their root forms, such as "discriminating" and "discrimination" being lemmatized into "discriminate". Moreover, tokens that share the same or similar meanings have been clustered into the same word. For instance, "house", "home", and "property" have been converted into "home". Following this synthesis step, nine key concepts have been identified from the data analysis, which aims to represent the crucial issues and concerns voiced by Airbnb hosts. Each of these key concepts has at least appeared once in each post. Lastly, all the key concepts were input into Gephi (Version 0.9.2), an open graph viz platform, to generate a visualized network based on their co-occurrences in each post (Figure 1). The size of the nodes indicates the frequency of these key concepts that has been mentioned throughout these posts. The thickness of the edge connecting two nodes signifies the weight of the cooccurrence between these two key concepts. The user names of the hosts, whose posts were quoted in this study, have been concealed and replaced by a pseudonym, such as "Host 1" and "Host 2" according to the order of appearance.

\section{FINDINGS AND DISCUSSION}

As illustrated in Figure 1, the nodes in the visualized network represent the most frequently mentioned key concepts by Airbnb hosts as indicated by their size. These nine key concepts are home, safety, stranger, risk, hotel, third-party booking, trust, community, and discriminate. These key concepts are connected based on their co-occurrence in these posts and its thickness indicates the weight of these co-occurred concepts, indicating the intertwined relationships among the key issues voiced by Airbnb hosts. The network shows what concerned Airbnb hosts the most towards this new non-discrimination policy of not showing guests' photos until accepting booking requests. "Home" is the most frequent key concept that appeared in these posts posted by Airbnb hosts who showed great concerns over accepting the booking requests without being able to the guests' photos and have strongly voiced their protection over their private space. Host 1 vented the feeling of frustration by stating "I think it is totally nonsense that people don't want to share their photos yet they expect us to share our homes. 
Nonsense!!! We need access to full profiles and reviews prior to accepting reservations." Many hosts have criticized this new policy of removing guests' photos and compared it to blind dates, for instance, Host 2 argued "I do not feel comfortable to accept bookings without a photo. If a dating site tried this they would not have any customers. It is just natural to want to see who you are talking to and inviting into your home. Especially for women letting part of their living areas." Roelofsen and Minca (2018) argue that hosts have sacrificed personal spaces in their homes to join the Airbnb platform. Although hosts want to commercialize their spaces, simultaneously they would like to retain certain rights and freedom within their private yet commercialized spaces (Farmaki et al., 2020; Farmaki and Kladou, 2020) without being seen as discriminatory. Farmaki et al. (2020) argue the transparency is crucial in representing the private space of hosts for guests to choose. In this context, it is also paramount for Airbnb to ensure transparency by disclosing guests' photos to hosts when guests make booking requests. Therefore, hosts have called upon all hosts to stand together and firm regarding the new policy to protect their homes. When introducing policies and regulations, Airbnb needs to consider not only the guests' rights of not being discriminated against but also hosts' rights to transparency. The second significant matter that concerned many hosts relates to the perceived safety among Airbnb hosts brought by not being able to identify the incoming guests via their profile photos, leading to potential safety issues when hosting the guests. Host 3 stated "Safety is my most important issue. This is my home not a hotel, not a government center, not a political center, not a halfway house for criminals, [sociopaths] or terrorist, not a charity organization etc." In particular, hosts who reside in apartment buildings expressed their safety concerns over not only themselves but also other residents and the neighborhood as a whole. For example, Host 4 pointed out that "It [is] important to know who you [are] renting to especially if it is in an apartment building. I have to protect the other tenants and the tenant. This is also why I greet the guests, show them the apartment and how everything works. If there is no profile photo and you do [not] know who you are renting to that is a [scary] thing." These quotes resonate with the findings that hosts' concerns over safety and security are rational and reasonable as Airbnb has not implemented sufficient rules and regulations to protect their hosts from potential issues (Gear, 2016), which may result in a negative impact on host satisfaction on Airbnb (Malazizi et al., 2018).

The next key concepts are about guests being strangers in hosts' homes and personal space, which posed tremendous risks to hosts. For P2P platforms like Airbnb, both parties do not know each other yet hosts choose to share their personal space with strangers (Liang et al., 2018; Moon et al., 2019). For example, Host 5 said that "As residents, we are already at a disadvantage, if not danger, by allowing total strangers into our homes. You are asking us to exposes ourselves even more than we are already doing. How is that even almost acceptable to hosts? And what about our responsibility to our neighbors?" For instance, The removal of guests' photos also posed potential risks as perceived by hosts, particularly those living with young children:

As a parent [of] three young kids, I am extremely uncomfortable renting out my spare room to a faceless stranger. Photos give visual clues to the sort of person you are. It seems that Airbnb has failed to [realize] that hosts are oftentimes renting out their homes that they live in and guests are sharing that space. For my husband and I, as parents, we want to see who is coming into our home. I [am] not happy with this new rule about photos at all and I hope Airbnb [realize] that this rule may prevent the tiny minority of hosts who do discriminate - and obviously this is totally unacceptable - from doing so. However, the vast majority of us hosts do not discriminate and would like to put a face to the person requesting to book so we get an idea of what sort of person we are letting into our homes. The whole idea behind Airbnb is sharing your home, not renting out hotel rooms. Come Airbnb, please listen to hosts on this as sadly, I think this policy, although [well-meaning], is wrong (Host 6).

Various studies have confirmed that profile photos play a bridging role during their initial interactions (Ert et al., 2016; Farmaki and Kladou, 2020), and characteristics of profile photos constitute one of the important attributes for hosts to assess the potential risks of granting permission to guests (Karlsson et al., 2017). For those hosts who were motivated by financial gains through sharing their personal space on Airbnb, they felt the urge to please the guests, thus suffering from the disadvantages in the power negotiation with potential guests (Farmaki and Kaniadakis, 2020). Thus, the removal of guests' profile photos takes away the foundation of host-guest interactions and trust on Airbnb.

As demonstrated in Figure 1, the lines that connect "home" to "stranger" and "safety" are particularly thicker, which represent that these key concepts have been co-occurring in these posts and the underlying safety concerns over inviting strangers into their homes brought by the new policy. For instance, Host 7 stated that "When a host opens their home to a stranger, they expect a gracious friend, not an entitled customer to take over their life. Yes, I absolutely want to see the face of the guest. [...] This is for the safety and comfort of both sides." Similarly, Host 8 pointed out that "We are renting our homes to the strangers that we do [not] know so we need to see who is booking and actually not only the person who books but also the people that they come with would be better for security [confirmation] reasons." It can be seen that there are multidimensional and correlational concerns among hosts revolving around this new policy of removing guests' photos.

Moreover, trust is defined as a "disposition to engage in social exchanges that involve uncertainty and vulnerability, but that are also potentially rewarding" (Bicchieri et al., 2004: 286). Airbnb was founded based on the mission of building a trustworthy home-sharing community between guests and hosts (Airbnb, 2016) who are strangers to each other. The trust needs to be established among three parties within P2P platforms, i.e., hosts, guests, and Airbnb in this case. However, many hosts considered that by withholding their access to guests' profile photos, Airbnb has made hosts vulnerable, undermined the trust-building among relevant parties, including hosts, guests, and the $\mathrm{P} 2 \mathrm{P}$ platform-Airbnb, and deviated from its motto to foster trust within the community. For instance, Host 9 claimed that "if I have to start a new relationship with a stranger, a picture of each other will help a lot and speed up the trust between the [two]". To a similar sense, Host 10 not only questioned how the removal of guests' photos would affect trust establishment but also voiced to seek retaliatory actions on her own profiles to balance things out:

[T] his is completely wrongheaded of Airbnb to protect the interest of a *potential* guest over the host who has so much more at stake. I'm a single woman living alone in my home; I [am] using my legal name on my profile; and I [am] using a clear full-face photo I of myself for all to see. I expect the exact same from potential guests. Or should I use a picture of my cat 
and an alias? How does that establish trust, which used to be the keyword of all Airbnb's marketing? From the perspectives of hosts, this step taken by Airbnb not only undermines the trust-building but also imposing far-reaching impacts on the Airbnb community. Host 11 stated "When I have a booking request from someone who has a goofy photo on their profile, I asked them to update it. I do this by explaining that Airbnb is built on community and being able to recognize one another when we meet in person. And, they can look at my profile for an example." To a similar vein, Host 12 hoped Airbnb would reconsider this new policy as contradictive to the spirit of the Airbnb community: "Knowing more about each other better reflects the spirit of home-sharing that Airbnb is supposed to be about. Guests who want an anonymous, faceless experience should book a motel. Knowing whether a guest 'looks trustworthy' may not be much to go on, but Airbnb should not strip hosts of our limited ability to exercise our judgment when creating a connection". Some home sharers expressed that they might delete their profile photos or put up an animal or plant photo instead, which may further deteriorate the trust-building efforts in the Airbnb community. Regarding the implementation of such a new policy, hosts are generally afraid of the guests who show up at their front doors are not the ones who made the bookings. These third-party bookings are very likely to pose extra risks on hosts:

Do you understand that if someone shows up who [is] not the person who booked, [Airbnb] considers it a 3rd party booking and you are [on] your own? Do you understand that without that photo you'd have no way of knowing? It [is] way too easy to lie and book for someone else without a recent photo and government photo ID with a matching credit card. It [is] not about discrimination, it's about overall host safety, and [Airbnb] has created a loophole in this to avoid liability if there are issues (Host 13).

I [am] always scared of retaliation. I have [not] had a situation like this but have had 3rd party bookings. Did [not] you know 3rd party bookings are not covered by Airbnb host guarantee. Now I ask you, how are we going to be able to tell they are who they say they are without having a profile picture. A boss booking for an employee, a friend booking for another... A family member booking for another. We are not covered! (Host 14).

More importantly, the connections among "third-party bookings", "home" and "hotel" warrant much attention. Since guests do not need to share their photos until their booking requests are confirmed, hosts fear to accept third-party guests into their homes, causing unnecessary and additional issues. To numerous hosts, it seems that Airbnb has gradually changed from a homesharing and trust-building community to becoming a hotel association where guests' rights are more favored. These hosts in no way agree with what Airbnb has implemented, Host 15 voiced the feeling of anger by saying "I am accepting almost every request except when there is a risk of harming the quietness of the community in the building. [My] home is not a hotel neither a [business] service." Similarly, Host 16 was equally concerned and expressed "This is nothing other than forcing INSTANT BOOKING we are becoming a HOTEL. Personal experiences are now plain bookings. Homeowners rights are gone."

It remains unknown whether such a policy would be effective in stopping alleged discriminatory acts on Airbnb, but it certainly failed to foster trust between both parties and decreased hosts' willingness to accept guests who do not have profile photos. Furthermore, third-party bookings have made hosts less flexible and willing to host these guests at their homes due to safety and security concerns (Farmaki and Kladou, 2020), and Airbnb not having sufficient rules to protect hosts (Gear, 2016).

The new policy of removing guests' photos was implemented to combat the issue of discrimination towards guests that occurred on Airbnb. However, apart from undermining the mutual trust within the community as perceived by hosts, the concept of "discriminate" identified by Airbnb hosts in this network reflected how they considered that the new nondiscrimination policy is one-sided and biased and felt they were discriminated against by it. For instance, It is awful to get inquiries/bookings without a picture and absolutely NO information about the person and be expected to answer "into the blind". It is [one-sided] and goes against the host (Host 17). This lack of guest photo is very one-sided. Hosts [cannot] see the guest, but, guests can see the hosts and inside our homes. So much for equality (Host 18). It is utterly ridiculous and dangerous to make hosts blind to guests['] appearance before they show up, and if we change our minds and decline them, then we are discriminated against by [Airbnb] and, it seems, the law! These are our homes and we have our rights too (Host 19). All [hosts] are currently subject to discrimination as well because our profiles must include a facial profile photo. I submitted my profile photo willingly and by doing so definitely do expect it to be made public to all [guests] before they Request to Book (Host 20).

Current literature has mainly focused on hosts discriminating against guests based on their race, name, and/or sexual orientations (Ahuja and Lyons, 2017; Cui et al., 2020; Edelman et al., 2017). Although researchers have begun to look into discrimination that aimed at hosts, these studies paid more attention to the economic side of the story, namely, racial minorities on Airbnb, such as Asians, Hispanics, African-Americans, tend to suffer from price differences as compared to their white counterparts (Edelman and Luca, 2014; Kakar et al., 2018; Wang et al., 2015). Although Farmaki and Kladou (2020) offered some insight into how this new policy limited Airbnb hosts' ability to select prospective guests, it emphasized the underlying reasons for hosts' discriminatory behaviors towards guests too. However, the findings in this study have placed the emphasis on allowing hosts' concerns towards this new policy to be voiced and heard.

\section{CONCLUSION}

Situated upon the digital discriminatory practices on $\mathrm{P} 2 \mathrm{P}$ accommodation platforms and the new non-discrimination policy of not revealing guests' profile photos to hosts until booking requests are confirmed, this study has looked into how Airbnb hosts had responded to this new policy by examining the posts shared by them on an affiliated Airbnb Community website. By analyzing these posts shared by Airbnb hosts, nine key concepts identified through the analysis were presented in a visualized network generated via Gephi. These key concepts include home, safety, stranger, risk, hotel, third-party booking, trust, community, and discriminate. The visualized network also illustrates the intertwined connections among these key concepts are multi-dimensional and correlational, indicating these concepts cannot be easily separated from one another. Moreover, the findings of this study offer a nuanced understanding of why the new non-discrimination policy of removing guests' photos upset Airbnb hosts and put them in a disadvantaged position. 


\section{Theoretical implications}

While existing studies have mainly focused on identifying the underlying reasons for the discriminatory practices of Airbnb hosts (e.g., Ahuja and Lyons, 2017; Cui et al., 2020; Edelman et al., 2017; Farmaki and Kladou, 2020), and the motivation of Airbnb hosts and their interactions with guests (Farmaki et al., 2020; Karlsson and Dolnicar, 2016; Karlsson et al., 2017), this study contributes to the existing literature and knowledge by suggesting that the new non-discrimination policy introduced and implemented by Airbnb to fight against digital discrimination has put Airbnb hosts in a vulnerable and disadvantaged position. The findings of this study have offered a nuanced understanding of narratives and voices of Airbnb hosts towards this new non-discrimination policy, which is an under-researched area under the context of increasing academic attention to hosts discriminating against guests on P2P accommodation platforms like Airbnb. In addition, this study has adopted the network software Gephi to visually present a holistic picture of the key concepts and their connections relating to the new policy. The network suggests that the issues that concern Airbnb hosts are intertwined, multi-dimensional, and correlational; therefore, it is imperative to incorporate their narratives and voices into the process of making new regulations and rules to facilitate the trustbuilding and foster a community atmosphere among three parties, namely, Airbnb, hosts, and guests and tackle potential issues arisen during the sharing experiences by minimizing the possible risks perceived by all parties.

It is a controversial yet overlooked topic as Airbnb hosts deemed the new policy discriminatory as a discriminatory act towards them. The findings of the study also argue that Airbnb hosts have been discriminated against by Airbnb because of the introduction and implementation of the new policy of not disclosing guests' photos to hosts. Since Airbnb hosts need to post their profile photos and pictures of their home, rented room and/or space and common areas, which may result in an inequivalent status between hosts and guests. Specifically, guests could view all the photos uploaded by hosts to choose their preferred accommodation, whereas hosts could only view guests' photos after they accept the booking request from guests. Also, the findings of the study suggest that Airbnb hosts are more concerned with a series of uncertain issues brought about by this new policy rather than undertaking discriminatory practices. The reason why hosts would like to maintain a flexible ability to select their prospective guests on Airbnb is that they want to ensure the safety of themselves, their family, and their homes rather than discriminating against guests based on their names, colors of skin, and sexual orientation, etc.

2. Practical Implications

Besides offering nuanced insights into hosts' attitudes towards the new policy and theoretical implications to the literature, this study also provides practical implications with regard to P2P accommodation platforms. Firstly, hosts regard profile photos of guests as an essential element of fostering trust along with past reviews and other information on their profiles (Ert et al., 2016), and most hosts displayed their personal photos and their homes for prospective guests to make informed decisions. The findings of this study suggest that P2P accommodation platforms like Airbnb need to consider and listen to the hosts' opinions before introducing and implementing new policies and regulation to ensure equality between hosts and guest and enhance hosts' practices and experiences in spite of its initial intention of fighting against alleged discriminatory practices. This is also essential to smooth the home-sharing experience and facilitate the mutual trust-building among guests, hosts, and P2P accommodation platforms like Airbnb. Secondly, as the idiom goes that "a photo is worth a thousand words", the characteristics of guests' profile photos, such as content, setting, facial expression, and gesture, etc., may indicate certain personalities and characters of those potential guests (Karlsson et al., 2017), thus creating certain assumptions and/or associations perceived by hosts. Therefore, Airbnb needs to better regulate the account settings and establish detailed guidelines about what can be used as a profile photo to minimize the possibility to develop certain assumptions and/or establish certain associations and among hosts. For example, Airbnb may consider forbidding someone to set up their account or send out booking requests if their profile photos do not meet specific criteria. Thirdly, Airbnb also needs to establish regulations to minimize the possibility of third-party bookings to ensure the rapport of the home-sharing community as well as the safety and security of both hosts and guests rather than turning homes into hotels. Moreover, guests, hosts, policymakers, and P2P accommodation platforms like Airbnb involved need to work together to form a better plan to not only fight against discriminatory acts on P2P platforms but also safeguard the legal rights of both parties. Last but not the least, the findings of the study indicate that Airbnb hosts may undertake retaliatory behaviors by taking down their listings on Airbnb and relisting their properties at other P2P accommodation platforms where their concerns and rights are better cared for and protected. Thus, this study calls for policymakers and government regulators to consider more relevant factors, such as the hosts' rights to accept booking requests and host-guest power balance, and evaluate the impacts on both parties involved when introducing new policies to reduce potential discriminatory practices on P2P accommodation platforms like Airbnb and find a better solution for a win-win situation.

3. Limitations and Future Research

This study has offered nuanced yet significant insights about the narratives and voices of Airbnb hosts towards the new nondiscrimination policy of moving beyond photos on Airbnb, but it is not without limitations. This study has collected the posts shared by Airbnb hosts from one particular community website. Future studies could use a variety of community websites of P2P accommodation platforms where hosts actively shared their opinions and perspectives in this regard to provide further insights. Meanwhile, this study has only collected and analyzed online data, so future studies could use different approaches to collect different types of data about how hosts responded to this non-discrimination policy. Moreover, this study only looked into the narratives and voices of Airbnb hosts in this matter, so future studies could delve into other stakeholders, such as guests, Airbnb, and other parties to provide a more holistic perspective about the impacts and implications of moving beyond photos. Furthermore, this study did not include the place of residence where hosts listed their shared space as one of the study subjects. Future studies could look at whether the places of residence play a role in how hosts react to certain policies from the P2P platform.

\section{REFERENCES}

Ahuja, R., \& Lyons, R.C. (2017). The silent treatment: LGBT discrimination in the sharing economy. No. tep1917, Department of Economics, Trinity College Dublin, Dublin, Ireland. 
Airbnb (2016). Fighting discrimination and creating a world where anyone can belong anywhere. https://blog.atairbnb.com/fightingdiscrimination-and-creating-a-world-where-anyone-can-belong-anywhere/

Bar, R., Tătar, C., \& Herman, G.V. (2016). Satisfaction degree rating of tourist services in Buziaş spa, Timiş County, Romania. GeoJournal of Tourism and Geosites. 18(2). 212-223.

Benner, K. (2016). Airbnb adopts rules to fight discrimination by its hosts. The New York Times. https://www.nytimes.com/2016/09/09/ technology/airbnb-anti-discrimination-rules.html

Bicchieri, C., Duffy, J., \& Tolle, G. (2004). Trust among strangers. Philosophy of Science, 71(3), 286-319. https://doi.org/10.1086/381411

Boros, L., Dudás, G., Kovalcsik, T., Papp, S., \& Vida, G. (2018). Airbnb in Budapest: analysing spatial patterns and room of hotels and peerto-peer accommodations. GeoJournal of Tourism and Geosites, 10(1), 26-38.

Camilleri, J., \& Neuhofer, B. (2017). Value co-creation and co-destruction in the Airbnb sharing economy. International Journal of Contemporary Hospitality Management, 29(9), 2322-2340. https://doi.org/10.1108/IJCHM-09-2016-0492

Cheng, M., \& Foley, C. (2018). The sharing economy and digital discrimination: The case of Airbnb. International Journal of Hospitality Management, 70, 95-98. https://doi.org/10.1016/j.iihm.2017.11.002

Cui, R., Li, J., \& Zhang, D.J. (2020). Reducing discrimination with reviews in the sharing economy: Evidence from field experiments on Airbnb. Management Science, 66(3), 1071-1094. https://doi.org/10.1287/mnsc.2018.3273

Dolnicar, S. (2018). Unique features of peer-to-peer accommodation networks. In S. Dolnicar (Eds.), Peer-to-Peer Accommodation Networks: Pushing the Boundaries (pp. 1-14). Goodfellow Publishers, Oxford. https://dx.doi.org/10.23912/9781911396512-3599

Edelman, B.G., \& Geradin, D. (2015). Efficiencies and regulatory shortcuts: How should we regulate companies like Airbnb and Uber. Stanford Technology Law Review, 19(2), 293-328. http://dx.doi.org/10.2139/ssrn.2658603

Edelman, B.G., \& Luca, M. (2014). Digital discrimination: The case of Airbnb.com. Harvard Business School NOM Unit Working Paper, (14-054). http://dx.doi.org/10.2139/ssrn.2377353

Edelman, B.G., Luca, M., \& Svirsky, D. (2017). Racial discrimination in the sharing economy: Evidence from a field experiment. American Economic Journal: Applied Economics. 9(2). 1-22. https://doi.org/10.1257/app.20160213

Ert, E., Fleischer. A.. \& Magen, N. (2016). Trust and reputation in the sharing economy: The role of personal photos in Airbnb. Tourism Management, 55, 62-73. https://doi.org/10.1016/i.tourman.2016.01.013

Fagerstrøm. A.. Pawar. S.. Sigurdsson. V.. Foxall. G.R.. \& Yani-de-Soriano. M. (2017). That personal profile image might jeopardize your rental opportunitv! On the relative impact of the seller's facial expressions upon buying behavior on Airbnb ${ }^{\mathrm{TM}}$. Computers in Human Behavior. 72. 123-131. https://doi.org/10.1016/i.chb.2017.02.029

Farmaki, A., Christou, P., \& Saveriades, A. (2020). A Lefebvrian analysis of Airbnb space. Annals of Tourism Research, 80, 102806. https://doi.org/10.1016/i.annals.2019.102806

Farmaki, A., \& Kaniadakis, A. (2020). Power dynamics in peer-to-peer accommodation: Insights from Airbnb hosts. International Journal of Hospitality Management, 89, 102571. https://doi.org/10.1016/i.ijhm.2020.102571

Farmaki, A., \& Kladou, S. (2020). Why do Airbnb hosts discriminate? Examining the sources and manifestations of discrimination in host practice. Journal of Hospitality and Tourism Management, 42, 181-189. https://doi.org/10.1016/i.ihtm.2020.01.005

Farmaki, A., Stergiou, D., \& Kaniadakis, A. (2019). Self-perceptions of Airbnb hosts' responsibility: a moral identity perspective. Journal of Sustainable Tourism, 1-21. https://doi.org/10.1080/09669582.2019.1707216

Gear. A.C. (2016). Host at vour own risk: Monitoring the legality of Airbnb rentals at the platform level. Doctoral Dissertation, Michigan State Universitv. Michigan. USA.

Glusac. E. (2016). As Airbnb grows. so do claims of discrimination. The New York Times. Retrieved from https://www.nytimes.com/ 2016/06/26/travel/airbnb-discrimination-lawsuit.html

Guttentag, D. (2015). Airbnb: Disruptive innovation and the rise of an informal tourism accommodation sector. Current Issues in Tourism, 18(12), 1192-1217. https://doi.org/10.1080/13683500.2013.827159

Guttentag, D. (2019). Progress on Airbnb: A literature review. Journal of Hospitality and Tourism Technology, 10(4), 814-844. https://doi.org/10.1108/JHTT-08-2018-0075

Kakar, V., Voelz, J.. Wu. J.. \& Franco. J. (2018). The visible host: Does race guide Airbnb rental rates in San Francisco? Journal of Housing Economics. 40.25-40. https://doi.org/10.1016/i.ihe.2017.08.001

Karlsson. L.. \& Dolnicar. S. (2016). Someone's been sleeping in my bed. Annals of Tourism Research, 58, 159-162. https://doi.org/ 10.1016/i.annals.2016.02.006

Karlsson. L.. Kemperman. A.. \& Dolnicar. S. (2017). May I sleep in your bed? Getting permission to book. Annals of Tourism Research, 62, 1-12. https://doi.org/10.1016/i.annals.2016.10.002

Kozinets. R.V. (2010). Netnographv: Doing ethnographic research online. Sage. London.

Levin, S. (2016). Airbnb adopts new rules in effort to fight racial discrimination by hosts. The Guardian. https://www.theguardian.com/ technology/2016/sep/08/airbnb-discrimination-policy-changes-racial-discrimination

Liang. L.J.. Choi. H.C.. \& Joppe, M. (2018). Exploring the relationship between satisfaction. trust and switching intention. repurchase intention in the context of Airbnb. International Journal of Hospitalitv Management. 69. 41-48. https://doi.org/10.1016/i.iihm.2017.10.015

Malazizi, N., Alipour, H., \& Olva, H. (2018). Risk perceptions of Airbnb hosts: Evidence from a Mediterranean island. Sustainability, 10(5), 1349-1372. https://doi.org/10.3390/su10051349

Mody, M., Suess, C., \& Dogru, T. (2019). Not in my backyard? Is the anti-Airbnb discourse truly warranted? Annals of Tourism Research, 74(C), 198-203. https://doi.org/10.1016/i.annals.2018.05.004

Moon, H., Miao, L., Hanks, L., \& Line, N.D. (2019). Peer-to-peer interactions: Perspectives of Airbnb guests and hosts. International Journal of Hospitality Management, 77, 405-414. https://doi.org/10.1016/i.iihm.2018.08.004

Murphy, L.W. (2016). Airbnb's work to fight discrimination and build inclusion. Report submitted to Airbnb, 1-32. https://blog.atairbnb. com/wp-content/uploads/2016/09/REPORT_Airbnbs-Work-to-Fight-Discrimination-and-Build-Inclusion.pdf

Murphy, L.W. (2019). Three year review-Airbnb's work to fight discrimination and build inclusion. Report submitted to Airbnb, 1-16. https://news.airbnb.com/wp-content/uploads/sites/4/2019/09/Airbnb Work-to-Fight-Discrimination 0909 3.pdf

Oskam, J., \& Boswiik, A. (2016). Airbnb: the future of networked hospitality businesses. Journal of Tourism Futures, 2(1), $22-42$. https://doi.org/10.1108/JTF-11-2015-0048

Pizam. A. (2014). Peer-to-peer travel: Blessing or blight?. International Journal of Hospitality Management, (38), 118-119. http://dx.doi.org/10.1016/i.iihm.2014.02.013

Roelofsen. M.. \& Minca, C. (2018). The Superhost. Biopolitics. home and community in the Airbnb dream-world of global hospitality. Geoforum, 91, 170-181. https://doi.org/10.1016/i.geoforum.2018.02.021

Tuttle. B. (2014). Marriott's CEO just made a pretty good sale pitch for ... Airbnb?. Money.com. https://money.com/marriott-airbnb-arnesorenson-neighborhoods/

Wang. D.. Xi. S.. \& Gilheany, J. (2015). The model minority? Not on Airbnb. com: A hedonic pricing model to quantify racial bias against Asian Americans. Technology Science, 2015090104. 